\title{
Trace Element Biochemistry
}

National Cancer Institute

\section{Source}

National Cancer Institute. Trace Element Biochemistry. NCI Thesaurus. Code C19074.

The branch of biochemistry concerned with the role of trace elements in metabolism. 